\title{
The Psychological Effects of Physicians' Communication Skills on COVID-19 Patients
}

This article was published in the following Dove Press journal:

Patient Preference and Adherence

\author{
Walid Al-Zyoud (1D) \\ Thelal Oweis $\mathbb{D}^{2}$ \\ Haytham Al-Thawabih $\mathbb{1}^{3}$ \\ Fawwaz Al-Saqqar (D) ${ }^{2}$ \\ Akeel Al-Kazwini ${ }^{1}$ \\ Fawzi Al-Hammouri (iD ${ }^{4}$ \\ 'School of Applied Medical Sciences, \\ German Jordanian University, Amman, \\ Jordan; ${ }^{2}$ School of Basic Sciences and \\ Humanities, German Jordanian \\ University, Amman, Jordan; ${ }^{3}$ School of \\ Applied Humanities and Languages, \\ German Jordanian University, Amman, \\ Jordan; ${ }^{4}$ Specialty Hospital Amman, \\ Amman, Jordan
}

Purpose: The COVID-19 pandemic has affected physician-patient communication (PPC) in multiple ways. This study aims to report on the impact of physician-patient communication (PPC) skills on COVID-19 patients' psychology in Jordan.

Sample and Methods: In this study, two questionnaires were designed. The first questionnaire targeted physicians, with 72 responses, and the second questionnaire targeted patients, with 248 responses. Both questionnaires contained common sections covering nine aspects of communication such as empathy, honesty, optimism, simple and deliberateness.

Results: This study found that the psychological effect of physicians' positive communication skills on COVID-19 patients is significant. There were almost statistical agreement between physicians' and patients' questionnaire responses that the physicians' communication skills have positively affected the patients' psychological status; all patients' responses confirmed this finding.

Conclusion: Based on this study's findings, appropriate and continuous training will advance physicians' communication skills in the form of exercises that could be as simple as class- or lecture-based activities, or using technology-based learning. Using a protocol or handbook to guide such communication is another essential strategy to enhance physicianpatient communication (PPC). The study recommends that physicians must be aware that PPC skills required may vary depending on whether they are dealing with a pandemic or non-pandemic situation. Generally, appropriate or positive communication skills are considered one of the main factors effecting patients' psychological responses to their diagnosis.

Keywords: psychological effects, communication skills, COVID-19, pandemic, physicians and patients

\section{Introduction}

Coronavirus disease-2019 (COVID-19) is a human disease caused by the novel coronavirus (SARS-CoV-2 or $\mathrm{HCoV}-19$ ), which was first reported in December 2019. The World Health Organization (WHO) declared COVID-19 a public health emergency in January $2020,{ }^{1}$ and a pandemic on March 11, 2020. It is worth mentioning that at that stage the infection rates of asymptomatic infections were relatively high, and infections among children and young adults were relatively low. ${ }^{2}$ Hence, having future incidence prediction tools like mathematical modelling is vital in forecasting the spread of COVID-19 to ultimately protect the healthcare systems in different countries all over the globe. ${ }^{3}$ Caring for COVID-19 patients encompasses the risk of healthcare workers becoming infected, which may predispose them to psychological concerns, such as anxiety, depression,
Correspondence: Walid Al-Zyoud German Jordanian University, Amman Madaba Street, P.O. Box 35247, Amman, III80, Jordan

Tel +96264294401

Fax +962 64300215

Email Walid.AIZyoud@gju.edu.jo
Patient Preference and Adherence 2021:15 677-690

677

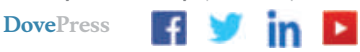

http://doi.org/10.2147/PPA.S303869 
and burnout. ${ }^{4,5}$ Medical trainees who were exposed to COVID-19 patients reported statistically significant incidences of higher stress levels. ${ }^{6}$

Further, $34.8 \%$ of the nurses and $41.6 \%$ of the physicians caring for COVID-19 patients experience sleep disturbances. $^{7}$ To protect medical practitioners and minimize their exposure to COVID-19, several institutions shifted to using Telemedicine and virtual services to sustain the care continuum by screening suspected patients whilst maintaining adequate distance. ${ }^{8}$ Despite Telemedicine's benefits, healthcare workers acknowledge that while some patients may report satisfaction, others may take longer to adjust to this communication method. ${ }^{9}$ One proposed Telemedicine approach is based on Artificial Intelligence techniques, such as deep learning for text processing and genetic algorithms. ${ }^{10}$ Another example is a cloud-based framework to reduce adverse mental health effects of COVID-19 among seafarers. ${ }^{11}$

The first COVID-19 case in Jordan was registered at the beginning of March 2020 in a Jordanian citizen returning from Italy. A state of emergency was declared in Jordan on March 19, 2020. At that time, the Jordanian government imposed home confinement instructions and movement restrictions. By the end of March 05, 2021, the Jordanian Ministry of Health had reported 417,934 confirmed cases; and 4862 deaths. ${ }^{1}$ According to the Jordanian Ministry of Health, on March 05, 2021, the number of active cases receiving hospital treatment for COVID-19 stood at 1931 patients; of whom 395 patients were in intensive care units (ICU). Further, 176 of these ICU patients were being supported by mechanical ventilation. $^{12}$ By the end of March 5, 2021, over 115289961 COVID-19 cases and 2,564,560 deaths had been reported globally to WHO. ${ }^{12}$

Communication is conveying ideas, thoughts, feelings, and attitude, both verbally and nonverbally. There are two primary forms of contact: verbal and nonverbal-verbal refers to words, and nonverbal refers to all communication that occurs using body movements. ${ }^{13}$ It is defined as "the transfer of information from one person to another, whether or not it elicits confidence". However, the information transferred must be understandable to the receiver. ${ }^{14}$ Having adequate communication skills is essential for personal success. In particular, physicians must maintain good communication skills to develop excellent physician-patient relationships. ${ }^{14,15}$ According to Reddy and Gupta, ${ }^{16}$ several factors influence the acceptance of the communicated information, such as social, cultural, literacy levels, and religious beliefs. Inadequate physician communication skills are considered one of the main barriers to good communication in physician-patient interactions. ${ }^{17,18}$ According to Kee et al (2018), physicians who do not make appropriate eye contact, have negative facial expressions, fail to listen to patients, and speak in a threatening manner are considered to have a crucial communication skills gap. $^{19}$ Meanwhile, $\mathrm{Ha}$ and Longnecker (2010) mentioned patients' anxiety and fear and unrealistic expectations as barriers for good communication. ${ }^{20}$ Having competent communication skills comes with remarkable benefits. For instance, good communication will reduce emotional distress among patients, higher symptom resolution, better control of chronic diseases, ${ }^{14}$ improved compliance and satisfaction, ${ }^{18}$ and a reduced risk of medical malpractice claims. ${ }^{21}$

The COVID-19 pandemic has transformed patient care; wearing personal protective equipment, maintaining distance and the use of Telemedicine may negatively affect physician-patient communication. ${ }^{22}$ Back et al stipulated that physicians must review their communication skills in times of pandemic; as the pandemic hits the hospital's resources of equipment and staff, every healthcare worker will feel short of time to talk to their patients; this is of importance, especially while communicating with the critically ill patients. ${ }^{23}$ During a pandemic, patients become stressed, sensitive, and even stigmatized; therefore, healthcare professionals should be extremely cautious in selecting their terminology, method, and time of communication. ${ }^{16}$ Finset et al recommended communicating openly and honestly, delivering consistent and specific information, and acknowledging emotional responses while communicating. ${ }^{24}$ Further, keeping a patient-centered approach, shared decision-making and articulating care goals are necessary communicative elements during a pandemic. $^{25}$

Appropriate physician-patient communication is characterized by sharing information to give compassionate and empowering care provision, with sensitivity to patient needs. $^{26,27}$ Several strategies can help physicians achieve this level of communication, such as assessing what the patient knows and what they want to know from both verbal and non-verbal signs to show empathy. Delivering information in small, simple pieces also helps to build patient trust. $^{21,23}$ Physicians must also be aware of a patient's cultural preferences regarding communication. ${ }^{28}$ Appropriate and continuous training, either lecture-based or technologybased online modules, will advance physicians' 
communication skills. ${ }^{29}$ Using a protocol to guide communication is another essential strategy to enhance physicianpatient communication. Several strategies are available for healthcare workers to select, according to the conversation context.

For instance, The SPIKES protocol (SPIKES: Setting; Perception; Invitation; Knowledge; Empathy; Summarizing) was found to be effective in communicating bad news with diverse populations. ${ }^{30,31}$ The CLASS protocol (Context, Listening, Acknowledge, Strategy, and Summary) is used for medical interviews. CONES (Context, Opening Shot, Narrative, Emotions, Strategy, and Summary) is used for discussing a medical error, while BUSTER (Be prepared, Use non-judgmental listening, the Six-second rule, Tell me more, Empathize and validate, and Respond with a wish statement) can be used to guide challenging conversations. Moreover, the EVE (Explore the Emotion, Validate the Emotion, and Empathic Response) is useful for any encounter where emotions present. ${ }^{16}$

The current study aims to identify essential communication skills that are used between physicians and COVID19 patients in Jordan. The study also aims to demonstrate the extent to which these skills differ from or coincide with communication around other diseases, given that this disease is considered a pandemic due to its rapid spread. In addition, it seeks to study the effect of communication skills, whether negative or positive, on the psychological aspect of COVID-19 patients. This approach highlights a key distinguishing feature of this study, in that it explores the differences between the communication skills required in pandemic situations and those used in nonpandemic conditions. Furthermore, it will demonstrate the psychological impact of those skills.

\section{Materials and Methods Study Design}

This study is based on the descriptive-analytical method. It aims at identifying the critical communication skills used by a physician with a COVID-19 patient. It further uncovers the extent of a positive effect of such skills on a COVID-19 patient's psychology. Two ÏNstitutional Review Board-approved electronic questionnaires were designed to collect the data, one for physicians and the other for COVID-19 patients (Supplementary Physician Questionnaire and Supplementary Patient Questionnaire). These questionnaires were then randomly distributed to physicians and COVID-19 patients as appropriate.
Gender, age or an academic level were not taken into consideration in the study variables.

\section{Participants}

The study targeted 100 physicians treating coronavirus patients in Jordan and (300) COVID-19 patients during or after 14 days of infection by SARS-CoV-2 treated by physicians either as inpatients or outpatients. Seventy-two physicians (72\%) responded, and 248 patients $(82.6 \%)$ responded by completing the questionnaires.

\section{Ethics}

The Institutional Review Board (IRB) of the Specialty Hospital approved the study proposal with the approval № $103667 / T / 1 / 5$ on 10/12/2020, and consent was obtained from all participants when the two questionnaires were distributed to COVID-19 patients and physicians who treat COVID-19 patients. It was explained to the physicians and patients that participation in this research was privacy-guaranteed and not obligatory. Participants were not asked to provide personal information such as their names, age, and education level. These criteria match the Declaration of Helsinki 1989. ${ }^{32,33}$ Both groups, physicians and patients, were informed that the questionnaire responses would be used for scientific research.

\section{Data Collection Procedure}

The data of the study were collected during December 2020, after ethical approval was obtained. In compliance with universal protocols to mitigate the pandemic's spread, the questionnaires were sent via email and over social media platforms. Patients who were unable to complete the electronic questionnaire were interviewed by phone to collect their responses.

\section{Research Instruments}

The first questionnaire was directed to physicians, aiming to determine the physician's communication skills with COVID-19 patients. It was built on 27 statements divided into nine sections (as shown in Table 1). This questionnaire was created based on communication aspects listed from a previous report about patient-physician communication. ${ }^{21}$

The second questionnaire was directed to COVID-19 patients who had been treated as inpatients or outpatients. It aimed to measure the physicians' communication skills in the nine topics used in the first questionnaire on COVID-19 patients' psychology. Both questionnaires were rated on a 5-point Likert scale as shown in Table 2. 
Table I The Nine Sections of the Questionnaire

\begin{tabular}{|c|c|}
\hline Section & $\begin{array}{l}\text { The Communication Aspect or Topic of Each } \\
\text { Section }\end{array}$ \\
\hline First & $\begin{array}{l}\text { Physician acceptance of patient pre-information and its } \\
\text { effect on the patient }\end{array}$ \\
\hline Second & $\begin{array}{l}\text { The extent to which the physician provides the patient } \\
\text { with information and its effect on the patient }\end{array}$ \\
\hline Third & $\begin{array}{l}\text { The extent of the physician's sympathy towards the } \\
\text { patient and its effect on the patient. }\end{array}$ \\
\hline Fourth & $\begin{array}{l}\text { The effect of the physician's slow and deliberate } \\
\text { communication strategy on the patient. }\end{array}$ \\
\hline Fifth & $\begin{array}{l}\text { The physician's simplification of the disease and its effect } \\
\text { on the patient. }\end{array}$ \\
\hline Sixth & $\begin{array}{l}\text { The extent of the physician's honesty and its effect on the } \\
\text { patient. }\end{array}$ \\
\hline Seventh & $\begin{array}{l}\text { The extent to which the physician gives hope and } \\
\text { optimism, and its effect on the patient. }\end{array}$ \\
\hline Eighth & $\begin{array}{l}\text { The extent of the physician's positive reaction and its } \\
\text { effect on the patient. }\end{array}$ \\
\hline Ninth & $\begin{array}{l}\text { The extent of the physician's negative reaction and its } \\
\text { effect on the patient. }\end{array}$ \\
\hline
\end{tabular}

Table 2 Five-Point Likert Scale

\begin{tabular}{|l|l|l|}
\hline Likert Scale & Interval & Description \\
\hline 1 & $1.00-1.79$ & Strongly Disagree \\
2 & $1.80-2.59$ & Disagree \\
3 & $2.60-3.39$ & Neutral \\
4 & $3.40-4.19$ & Agree \\
5 & $4.20-5.00$ & Strongly Agree \\
\hline
\end{tabular}

To ensure the validity of the questionnaire, health and communication skills specialists reviewed the questionnaires to verify their statements. In addition, a pilot session was conducted on (5) physicians and (10) patients who did not take part in the overall study, to verify their understanding of the questionnaire paragraphs and inform the researchers of any issues they faced with its completion. This information was analyzed using Cronbach alpha $(\alpha)$ value to assess the questionnaire's reliability coefficient factor. Both questionnaires reached a reliability coefficient factor $(\geq 0.80$ ), indicating statistical reliability at $p$-value (0.01) level, which means that both questionnaires are valid and reliable.

\section{Data Analysis}

All data collected through the study were converted from written to digital data. Subsequently, these data were analyzed according to the statistics nonparametric test
(Kruskal-Wallis $H$ ) using the (IBM-SPSS v.26) program (Supplementary Raw Data).

\section{Results}

Table 3 (first section) shows that physicians accepted preinformation and opinions from patients concerning their medical condition, but with no statistical significance at p-value (0.840). Patients also felt comfortable that the physicians were attentive and accepting of their information and opinions, which the p-value confirms at the level of (0.764). Generally, this indicates that there are no statistically significant differences between physicians' responses and patients' responses in this regard. However, the table does reveal statistically significant differences at p-value (0.001) between physicians' responses and patients' responses in Q2. This indicates that physicians have reservations about patients' medical opinions (Figure 1). The statistically significant differences confirm this among the physicians' responses (Appendix A in the supplementary materials).

Table 3 (second section) shows that physicians agree to provide patients with information concerning their medical condition, positively affecting the patients' psychological state by reducing fear and anxiety among patients. The $p$-value confirms this at the level of $(0.070)$. There is no statistically significant difference between the responses of physicians and the reactions of patients. However, it shows explicitly that there is a statistically significant difference at the level of p-value (0.004) between responses of physicians and responses of patients in Q5, which means that physicians have reservations about the nature of the information requested by the patients (Figure 2). The statistically significant differences confirm this among the physicians' responses (Appendix B in the supplementary materials).

Table 3 (third section) shows that physicians believe that they show sympathy towards patients, positively affecting the patients' psychological state. Despite physicians and patients' compatibility, there is a statistically significant difference at p-value (0.001), which indicates that physicians exaggerate sympathy with patients (Figure 3 ). This is confirmed by statistically significant differences at p-value (0.001) among the physicians' questionnaire responses (Appendix $\mathrm{C}$ in the supplementary materials).

Table 3 (fourth section) shows that physicians believe that it is important to speak slowly and explain treatment procedures without overburdening the patient with test results. Patient responses confirm that this approach by physicians positively affects them. What affirms the 
Table 3 General Trend of the Physicians' and Patients' Questionnaire Responses

\begin{tabular}{|c|c|c|c|c|}
\hline Physicians' Responses & Level & Patients' Responses & Level & $\begin{array}{l}\text { Sig. at } \\
(\alpha \leq 0.05)\end{array}$ \\
\hline \multicolumn{5}{|c|}{ First Section } \\
\hline $\begin{array}{l}\text { First Section: Physician's acceptance of pre- } \\
\text { information from patients. }\end{array}$ & & $\begin{array}{l}\text { First Section: The effect of the physician's acceptance of the } \\
\text { patient's pre-information. }\end{array}$ & & \\
\hline $\begin{array}{l}\text { QI: I accept the information that the patient } \\
\text { provides me with. }\end{array}$ & $\begin{array}{l}\text { Strongly } \\
\text { Agree }\end{array}$ & $\begin{array}{l}\text { QI: The physician's acceptance of the information I provide } \\
\text { to him/her made me aware of his/her interest in my } \\
\text { condition. }\end{array}$ & $\begin{array}{l}\text { Strongly } \\
\text { Agree }\end{array}$ & No \\
\hline $\begin{array}{l}\text { Q2: I accept the patient's opinion on his/her } \\
\text { medical condition. }\end{array}$ & Agree & Q2: I felt good when the physician accepted my opinion. & Agree & Yes \\
\hline $\begin{array}{l}\text { Q3: I advise the patient not to believe the } \\
\text { information found on social media. }\end{array}$ & $\begin{array}{l}\text { Strongly } \\
\text { Agree }\end{array}$ & $\begin{array}{l}\text { Q3: The physician's advice not to believe the information } \\
\text { I found on social media has positively impacted my mood. }\end{array}$ & $\begin{array}{l}\text { Strongly } \\
\text { Agree }\end{array}$ & Yes \\
\hline All Questions (Average) & $\begin{array}{l}\text { Strongly } \\
\text { Agree }\end{array}$ & & $\begin{array}{l}\text { Strongly } \\
\text { Agree }\end{array}$ & No \\
\hline \multicolumn{5}{|c|}{ Second Section } \\
\hline $\begin{array}{l}\text { Second Section: The extent to which the } \\
\text { physician provides the patient with } \\
\text { information. }\end{array}$ & & $\begin{array}{l}\text { Second Section: The effect of providing the patient with } \\
\text { information. }\end{array}$ & & \\
\hline $\begin{array}{l}\text { Q4: I inform the patient of positive disease } \\
\text { statistics periodically. }\end{array}$ & Agree & $\begin{array}{l}\text { Q4: Sharing of positive disease statistics by the physician } \\
\text { reduced my fear of the symptoms of the disease. }\end{array}$ & Agree & No \\
\hline $\begin{array}{l}\text { Q5: I provide the patient with the } \\
\text { information they want. }\end{array}$ & Agree & $\begin{array}{l}\text { Q5: My physician's information on my case helped reduce my } \\
\text { anxiety. }\end{array}$ & Agree & Yes \\
\hline $\begin{array}{l}\text { Q6: I frequently answer patient's inquiries } \\
\text { about the disease. }\end{array}$ & Agree & $\begin{array}{l}\text { Q6: The physician's answers to my frequent inquiries about } \\
\text { the disease reassured me about the status of my health. }\end{array}$ & Agree & No \\
\hline All Questions (Average) & Agree & & Agree & No \\
\hline \multicolumn{5}{|c|}{ Third Section } \\
\hline $\begin{array}{l}\text { Third Section: The extent of the physician's } \\
\text { sympathy towards the patient. }\end{array}$ & & Third Section: The effect of the physician's sympathy. & & \\
\hline $\begin{array}{l}\text { Q7: I present a friendly expression on my } \\
\text { face when I contact the patient. }\end{array}$ & $\begin{array}{l}\text { Strongly } \\
\text { Agree }\end{array}$ & Q7: The physician's facial expression comforted me. & Agree & Yes \\
\hline $\begin{array}{l}\text { Q8: I use polite phrases like (father, mother, } \\
\text { brother, my dear ...) when talking to the } \\
\text { patient. }\end{array}$ & $\begin{array}{l}\text { Strongly } \\
\text { Agree }\end{array}$ & $\begin{array}{l}\text { Q8: The physician's use of polite phrases when describing my } \\
\text { illness eased my fears and anxiety. }\end{array}$ & Agree & Yes \\
\hline Q9: I sit next to the patient. & Neutral & $\begin{array}{l}\text { Q9: The physician positioning himself/herself next to me gave } \\
\text { me comfort. }\end{array}$ & Agree & Yes \\
\hline All Questions (Average) & Agree & & Agree & Yes \\
\hline \multicolumn{5}{|c|}{ Fourth Section } \\
\hline $\begin{array}{l}\text { Fourth Section: The physician's strategy } \\
\text { (slow down). }\end{array}$ & & $\begin{array}{l}\text { Fourth Section: The effect of the physician's strategy (slow } \\
\text { down). }\end{array}$ & & \\
\hline QI0: I talk slowly to the patient. & $\begin{array}{l}\text { Strongly } \\
\text { Agree }\end{array}$ & $\begin{array}{l}\text { Q10: The physicians' slow pace when talking to me gave the } \\
\text { impression that he was interested in my case. }\end{array}$ & Agree & No \\
\hline
\end{tabular}


Table 3 (Continued).

\begin{tabular}{|c|c|c|c|c|}
\hline Physicians' Responses & Level & Patients' Responses & Level & $\begin{array}{l}\text { Sig. at } \\
(\alpha \leq \mathbf{0 . 0 5})\end{array}$ \\
\hline $\begin{array}{l}\text { QII: I do not burden the patient with } \\
\text { medical test results and procedures. }\end{array}$ & Agree & $\begin{array}{l}\text { QI I: Not being overwhelmed with the physician's medical } \\
\text { information and procedures positively impacted my mood. }\end{array}$ & Agree & No \\
\hline $\begin{array}{l}\text { Q I2: I take the time to explain the patient's } \\
\text { treatment procedures. }\end{array}$ & $\begin{array}{l}\text { Strongly } \\
\text { Agree }\end{array}$ & $\begin{array}{l}\text { Q12: By explaining my treatment procedures slowly, the } \\
\text { physician helped to increase my confidence in these } \\
\text { procedures. }\end{array}$ & Agree & No \\
\hline All Questions (Average) & Agree & & Agree & No \\
\hline \multicolumn{5}{|c|}{ Fifth Section } \\
\hline $\begin{array}{l}\text { Fifth Section: The extent to which the } \\
\text { physician simplifies the disease for the } \\
\text { patient. }\end{array}$ & & $\begin{array}{l}\text { Fifth Section: The effect of the physician simplifying my } \\
\text { disease for me. }\end{array}$ & & \\
\hline $\begin{array}{l}\text { QI3: I use the patient's laboratory reports } \\
\text { to describe their condition frankly. }\end{array}$ & Agree & $\begin{array}{l}\text { Q13: By not sharing my laboratory reports when describing } \\
\text { my condition, the physician reduced my anxiety. }\end{array}$ & Agree & No \\
\hline $\begin{array}{l}\text { Q I4: I take time to explain the patient's } \\
\text { medical condition to him/her. }\end{array}$ & Agree & $\begin{array}{l}\text { Q14: The physician's detailed explanation of my condition } \\
\text { affected me positively. }\end{array}$ & Agree & No \\
\hline $\begin{array}{l}\text { QI5: I use common and simple terms to } \\
\text { describe the patient's condition to him/her. }\end{array}$ & $\begin{array}{l}\text { Strongly } \\
\text { Agree }\end{array}$ & $\begin{array}{l}\text { Q15: Using common and simple terms while describing my } \\
\text { condition reduced my anxiety. }\end{array}$ & Agree & Yes \\
\hline All Questions (Average) & Agree & & Agree & No \\
\hline \multicolumn{5}{|c|}{ Sixth Section } \\
\hline $\begin{array}{l}\text { Sixth Section: The extent of the physician's } \\
\text { honesty with the patients. }\end{array}$ & & $\begin{array}{l}\text { Sixth Section: The effect of the physician's honesty with the } \\
\text { patients. }\end{array}$ & & \\
\hline $\begin{array}{l}\text { Q I6: I am honest with the patient regarding } \\
\text { the details of their medical condition. }\end{array}$ & Agree & $\begin{array}{l}\text { Q16: The physician's frankness motivated me to implement } \\
\text { his instructions fully. }\end{array}$ & $\begin{array}{l}\text { Strongly } \\
\text { Agree }\end{array}$ & No \\
\hline $\begin{array}{l}\text { QI7: I inform the patient that the symptoms } \\
\text { of the disease will develop over time. }\end{array}$ & Neutral & $\begin{array}{l}\text { Q17: The physician's detailed explanation of the symptoms' } \\
\text { development increased my interest in obeying the physician } \\
\text { instructions. }\end{array}$ & Agree & Yes \\
\hline $\begin{array}{l}\text { QI8: I sympathetically inform the patient } \\
\text { that there is no current treatment. }\end{array}$ & Agree & $\begin{array}{l}\text { Q18: Being informed by the physician that there is no } \\
\text { current treatment for the disease helped me to adhere fully } \\
\text { to the physician's instructions. }\end{array}$ & Agree & No \\
\hline All Questions (Average) & Agree & & Agree & Yes \\
\hline \multicolumn{5}{|c|}{ Seventh Section } \\
\hline $\begin{array}{l}\text { Seventh Section: The extent to which the } \\
\text { physician gives hope and optimism to the } \\
\text { patients. }\end{array}$ & & $\begin{array}{l}\text { Seventh Section: The effect of the physician giving the patient } \\
\text { hope and optimism. }\end{array}$ & & \\
\hline $\begin{array}{l}\text { Q19: I downplay disease symptoms when } \\
\text { talking to the patient. }\end{array}$ & Neutral & $\begin{array}{l}\text { Q19: The physician's downplaying of the symptoms of the } \\
\text { disease raised my spirits. }\end{array}$ & Agree & Yes \\
\hline $\begin{array}{l}\text { Q20: I use encouraging words to support } \\
\text { the patient. }\end{array}$ & $\begin{array}{l}\text { Strongly } \\
\text { Agree }\end{array}$ & $\begin{array}{l}\text { Q20: The encouraging words used by the physician boosted } \\
\text { my self-confidence. }\end{array}$ & Agree & Yes \\
\hline $\begin{array}{l}\text { Q21: I provide the patient with optimistic } \\
\text { new scientific information on the disease. }\end{array}$ & $\begin{array}{l}\text { Strongly } \\
\text { Agree }\end{array}$ & $\begin{array}{l}\text { Q21: Providing me with optimistic new scientific information } \\
\text { on the disease improved my mood. }\end{array}$ & Agree & Yes \\
\hline
\end{tabular}

(Continued) 
Table 3 (Continued).

\begin{tabular}{|c|c|c|c|c|}
\hline Physicians' Responses & Level & Patients' Responses & Level & $\begin{array}{l}\text { Sig. at } \\
(\alpha \leq \mathbf{0 . 0 5})\end{array}$ \\
\hline All Questions (Average) & Agree & & Agree & No \\
\hline \multicolumn{5}{|c|}{ Eighth Section } \\
\hline $\begin{array}{l}\text { Eighth Section: The extent of the physician's } \\
\text { positive reaction to the patients. }\end{array}$ & & $\begin{array}{l}\text { Eighth Section: The effect on me of the physician's positive } \\
\text { response. }\end{array}$ & & \\
\hline $\begin{array}{l}\text { Q22: I share with the patient my happiness if } \\
\text { their condition improves. }\end{array}$ & $\begin{array}{l}\text { Strongly } \\
\text { Agree }\end{array}$ & $\begin{array}{l}\text { Q22: The physician's positive reaction towards my results } \\
\text { raised my spirits. }\end{array}$ & $\begin{array}{l}\text { Strongly } \\
\text { Agree }\end{array}$ & Yes \\
\hline $\begin{array}{l}\text { Q23: I maintain eye contact with the patient } \\
\text { when talking to him/her. }\end{array}$ & $\begin{array}{l}\text { Strongly } \\
\text { Agree }\end{array}$ & $\begin{array}{l}\text { Q23: The physician's eye contact with me improved my } \\
\text { mood. }\end{array}$ & Agree & Yes \\
\hline $\begin{array}{l}\text { Q24: I sit next to the patient, and I respect } \\
\text { social distancing while comforting the } \\
\text { patient. }\end{array}$ & Neutral & $\begin{array}{l}\text { Q24: The physician sitting next to me while explaining my } \\
\text { condition made me feel important to him. }\end{array}$ & Agree & No \\
\hline All Questions (Average) & Agree & & Agree & No \\
\hline \multicolumn{5}{|c|}{ Ninth Section } \\
\hline $\begin{array}{l}\text { Ninth Section: The extent of the physician's } \\
\text { negative reaction to the patients. }\end{array}$ & & $\begin{array}{l}\text { Ninth Section: The effect of the physician's negative } \\
\text { response. }\end{array}$ & & \\
\hline $\begin{array}{l}\text { Q25: I use firm language with the patient } \\
\text { when he/she is not responding to } \\
\text { instructions. }\end{array}$ & Neutral & $\begin{array}{l}\text { Q25: The physician's use of firm language affected my ability } \\
\text { to follow the treatment prescribed. }\end{array}$ & Agree & Yes \\
\hline $\begin{array}{l}\text { Q26: My work stress affects my } \\
\text { communication with the patient. }\end{array}$ & Neutral & $\begin{array}{l}\text { Q26: The physician's anxiety affected the acceptance of my } \\
\text { health condition negatively. }\end{array}$ & Agree & Yes \\
\hline $\begin{array}{l}\text { Q27: I get distracted by outside influences, } \\
\text { people or the telephone while } \\
\text { communicating with the patient. }\end{array}$ & Agree & $\begin{array}{l}\text { Q27: The physician's preoccupation with other things while } \\
\text { communicating with me affected my acceptance of his views. }\end{array}$ & Agree & Yes \\
\hline All Questions (Average) & Neutral & & Agree & Yes \\
\hline
\end{tabular}

Abbreviation: Sig., statistically significant.

compatibility of these results is the p-value at the level of (0.855). The responses of physicians and patients are not dispersed (Figure 4). This is confirmed by statistically significant differences at $\mathrm{p}$-value (0.032) among the physicians' questionnaire questions (Appendix D in the sup plementary materials).

Table 3 (fifth section) shows that physicians agree to simplify the disease for patients, positively affecting the patients' psychological state by reducing anxiety and stress, as confirmed by the statistically significant differences at p-value (0.778). However, there are differences in Q15 in particular, which demonstrates statistical significant at p-value (0.002) (Appendix E in the supplementary materials). Figure 5 also shows the dispersion of physicians and patients' responses in Q13.
Table 3 (sixth section) shows that physicians' desire to be honest with patients regarding their medical condition is reflected in the patients' responses. The table indicates that physicians' honesty positively affects patients' motivation, interest, and seriousness in dealing with physicians' instructions and medical procedures. Despite the compatibility of physicians and patients, there is a statistically significant difference at p-value (0.000); also, there is a statistically significant difference at p-value (0.001) in Q17 between physicians' and patients' responses (Figure 6). This is confirmed by the statistically significant differences at $\mathrm{p}$-value (0.001) among the physicians' questionnaire responses (Appendix F in the supplementary materials).

Table 3 (seventh section) shows that physicians are willing to give patients hope and optimism, which 


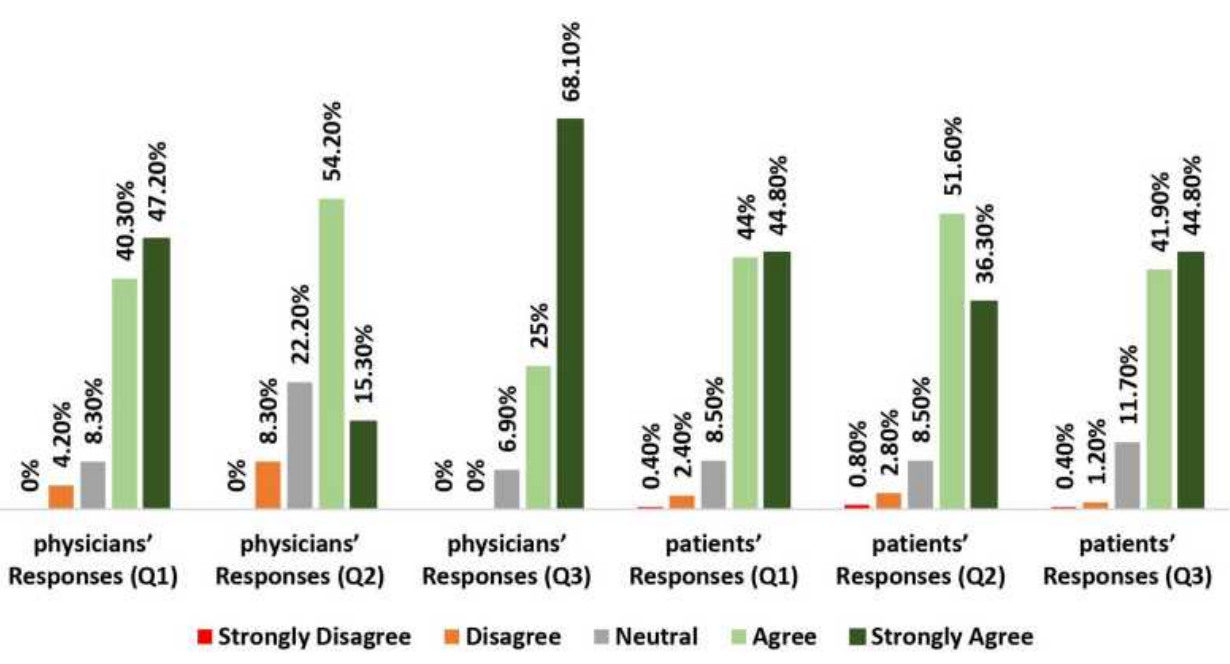

Figure I Distribution of responses of physicians and patients in the first section.

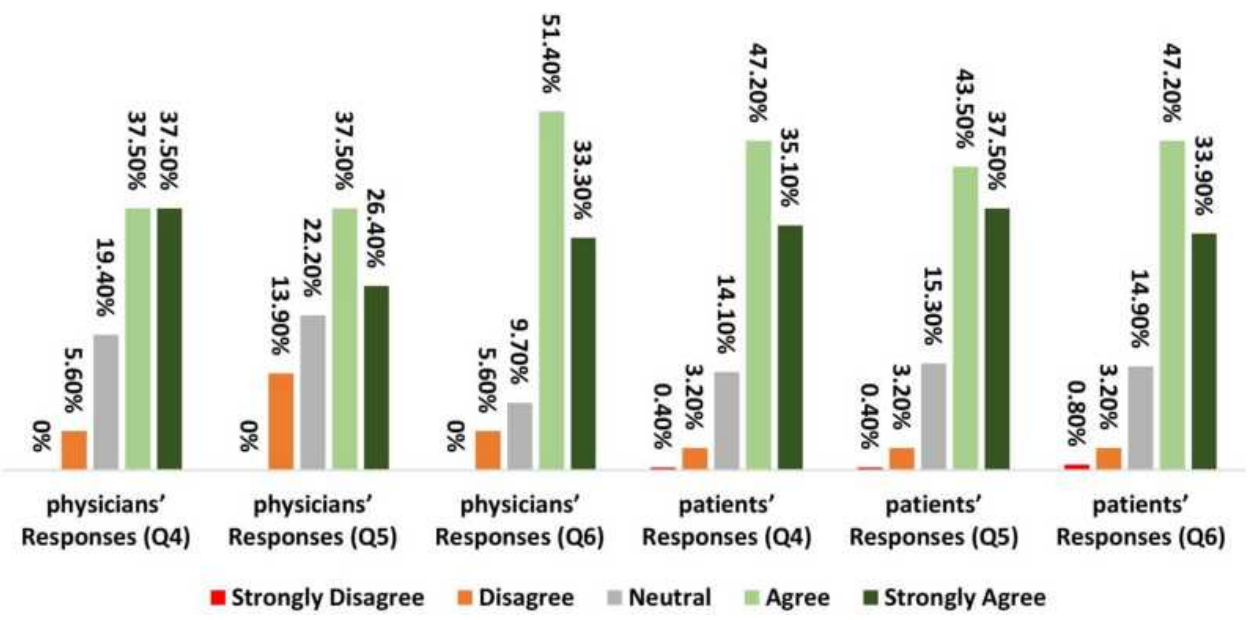

Figure 2 Distribution of responses of physicians and patients in the second section.

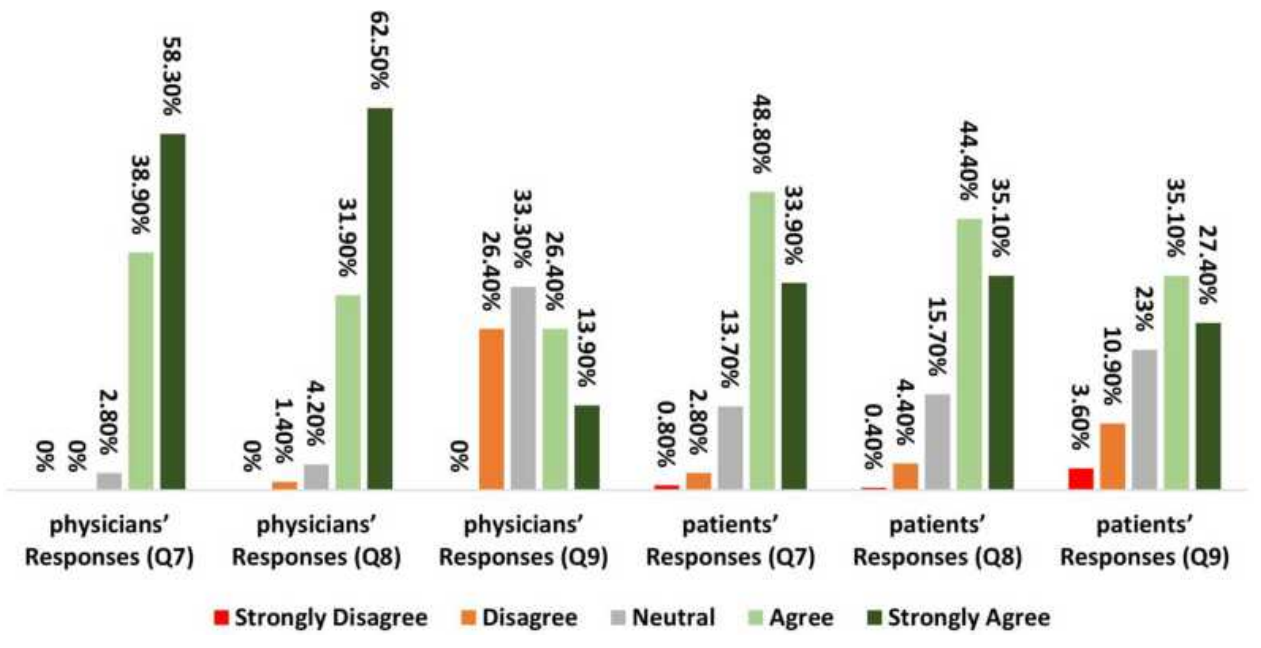

Figure 3 Distribution of responses of physicians and patients in the third section. 


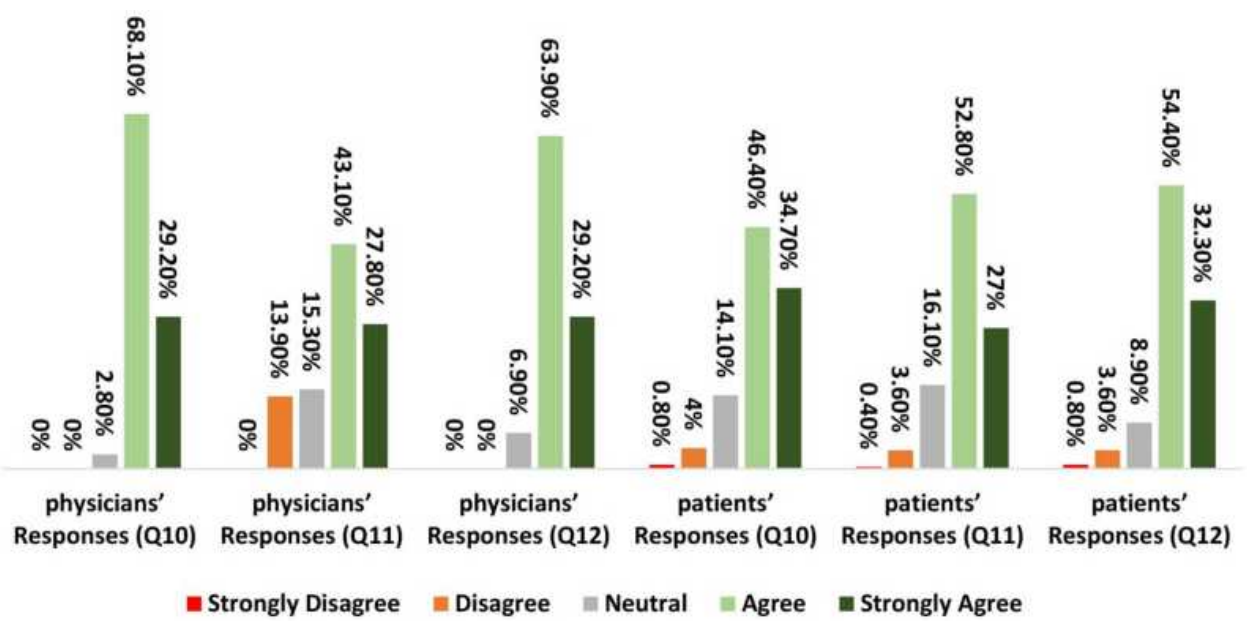

Figure 4 Distribution of responses of physicians and patients in the fourth section.

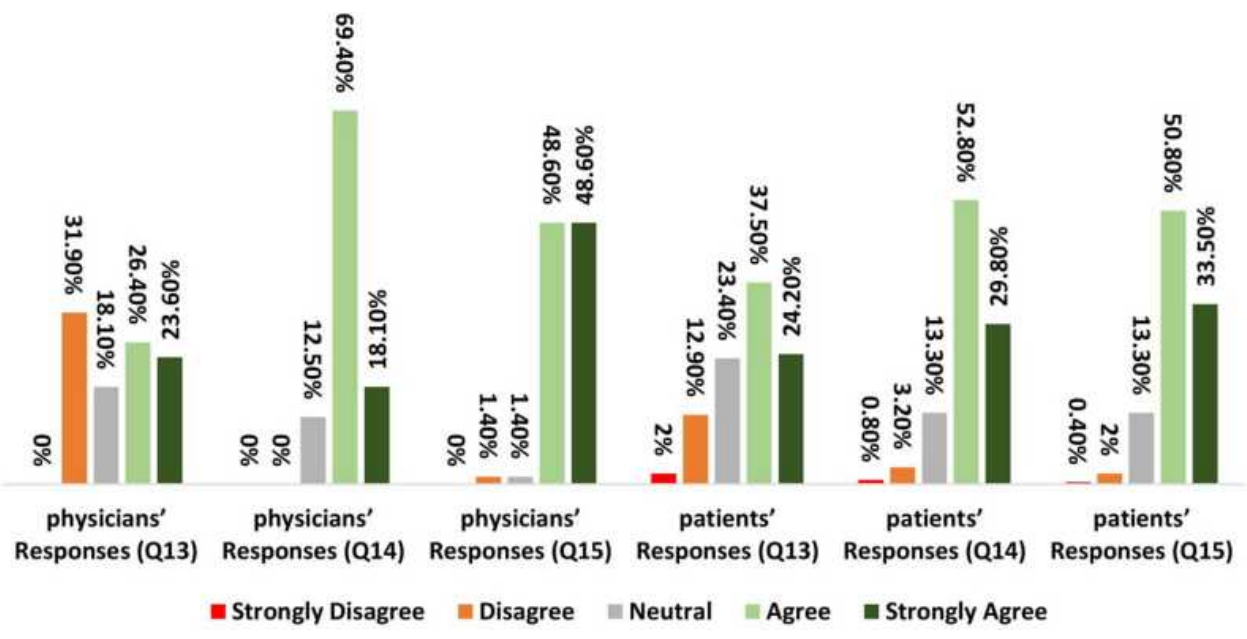

Figure 5 Distribution of responses of physicians and patients in the fifth section.

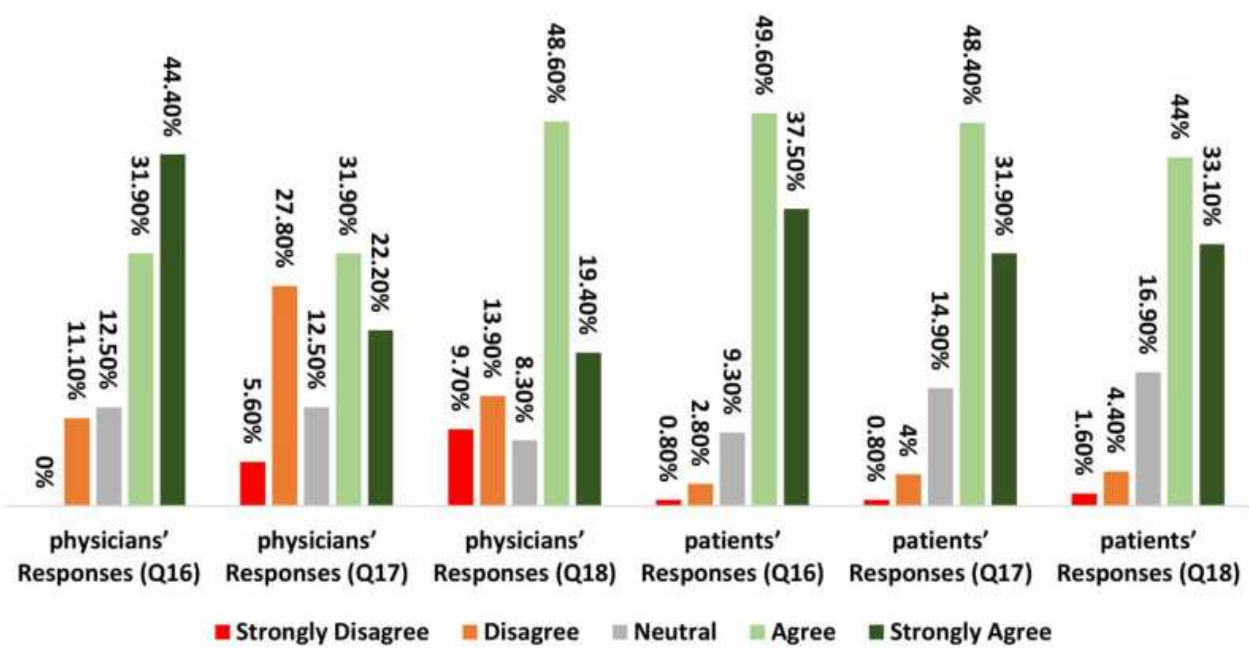

Figure 6 Distribution of responses of physicians and patients in sixth section. 
enhanced the patient's confidence in facing the disease. The compatibility of the two samples is shown in the lack of statistically significant difference between the two responses at p-value (0.185). However, there is a statistically significant difference in Q19. This is shown by the dispersion of the physicians' responses (Figure 7), which confirms the previous results of the statistically significant differences among the physicians' questions (Appendix G in the supplementary materials).

Table 3 (eighth section) shows that physicians indicated that their reaction towards patients is positive. Patients mirrored this, answering affirmatively about the positive psychological impact that physicians' positive responses had on them, and the statistical significance was generally at p-value (0.698). The distribution of physicians' responses observed in Q24 (Figure 8), reflects statistically significant differences among the physicians' questionnaire responses (Appendix H in the supplementary $\underline{\text { materials). }}$.

Table 3 (ninth section) shows that physicians are neutral in showing adverse reactions to patients, however, the patients agreed on the negative psychological impact. This shows the two samples' incompatibility, and it has been confirmed by a statistically significant difference at p-value (0.001) (Appendix I in the supplementary materi $\underline{\text { als}}$. This was also shown by the range of their responses (Figure 9).

\section{Discussion}

Breaking negative news is a frustrating and yet inevitable feature of health care for physicians and patients alike. Although, as our review of the related literature has

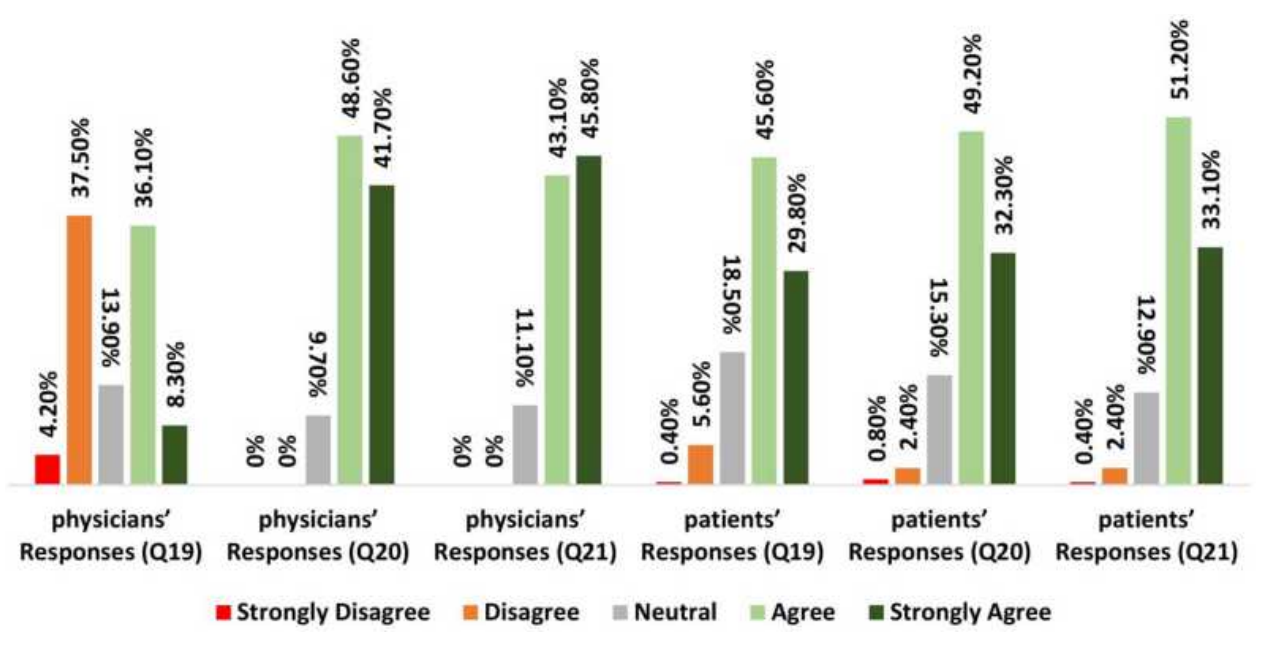

Figure 7 Distribution of responses of physicians and patients in the seventh section.

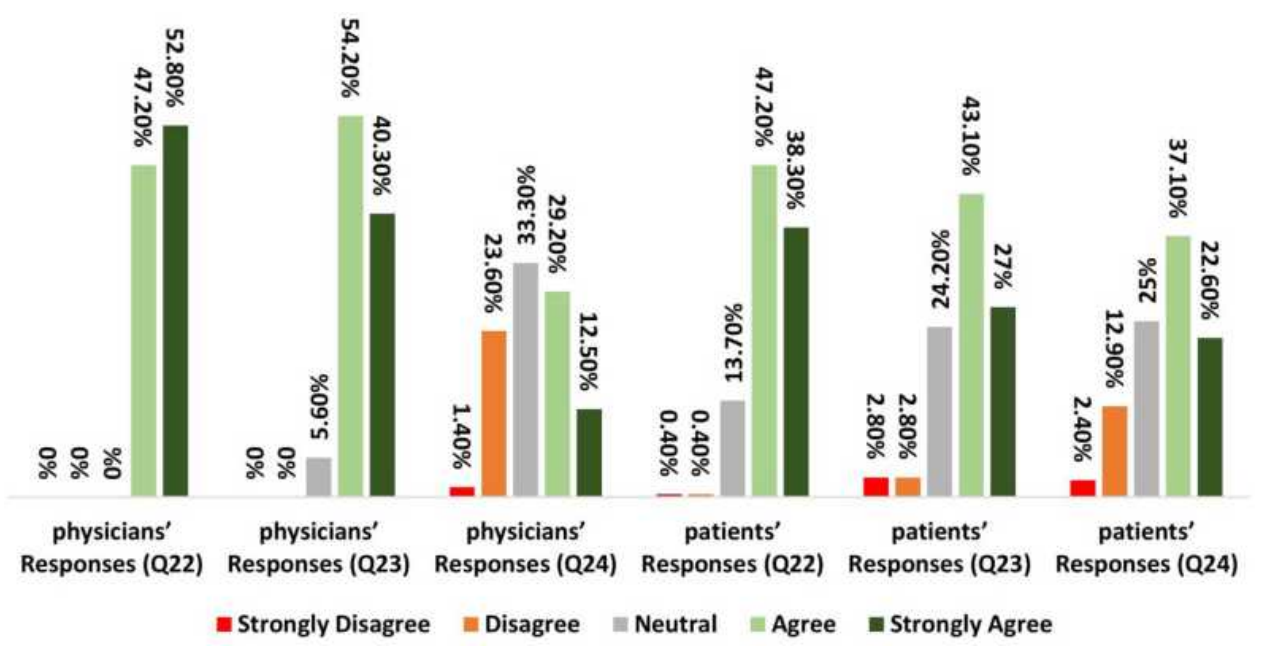

Figure 8 Distribution of responses of physicians and patients in the eighth section. 


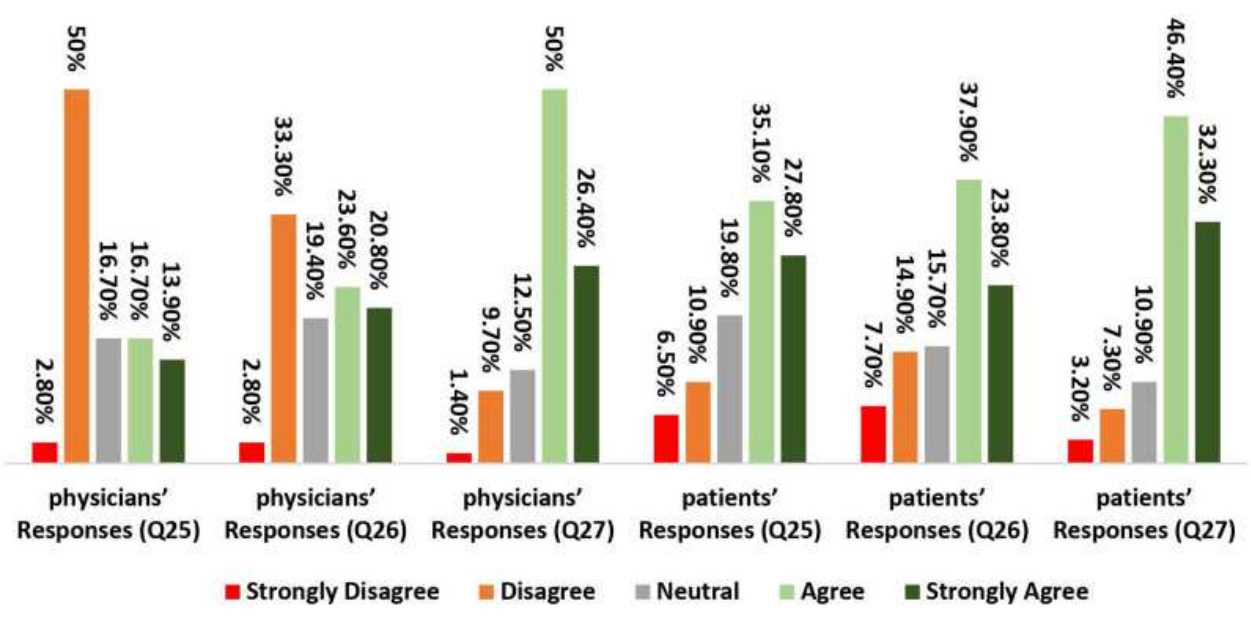

Figure 9 Distribution of responses of physicians and patients in the ninth section.

demonstrated, some approaches are considered better than others for breaking bad news. This study explores the beneficial impacts of physicians' positive communication strategies on the psychological wellbeing of COVID-19 patients. In brief, this study's findings implied the following: COVID-19 patients felt comfortable when getting the physician's attention and affection, which increased their confidence in the medical procedures. In addition, physicians' emotional involvement increased patients' selfconfidence and comfort. It reduced their anxiety and stress, and lastly, patients were less likely to receive treatment and accept their health situation when the physicians' opinions were perceived as negative.

The results of section one of the physicians' questionnaire in Figure 1 and Table 3 (first section) showed that physicians are generally able to accept patients' presentation and interpretation of their symptoms; pre-information was general chat about the patient, including his/her opinion about her or his medical condition. However, some physicians expressed reservations regarding patients' medical beliefs because they believe that medical opinions can come only from qualified persons such as physicians, pharmacists, nurses, et cetera. Besides which, the preinformation included advice from the physician to the patient to reject any unspecialized information propagated via social media. Findings from the first section of the patients' questionnaires correlated with this, suggesting that patients also experienced acceptance of their preinformation given.

The second section was about the skills of physicians to effectively communicate scientific and medical information about COVID-19. The results of section 2 in Figure 2 and Table 3, (second section) showed physicians' general ability to communicate medical information and statistics about COVID-19 with their patients. Some physicians expressed reservations regarding the value of sharing such information with patients because they believe that pandemic diseases are not fully understood, meaning information has to be shared with the public carefully. From the patients' point of view, section two showed that physicians' skills in communicating medical and statistical information about COVID-19 with them had a positive impact. This concurs with a previous study of Finset and his colleagues in terms of the importance of clear physician-to-patient communication as a key factor to fight the pandemic of COVID-19. ${ }^{24}$

The third section was about physicians' interpersonal skills; wearing a friendly expression, using polite phrases and sitting beside the patients. The results of section 3 in Figure 3) and Table 3, (third section) revealed a positive trend toward using polite and friendly expressions when talking with patients. However, physicians' reactions towards sitting beside their patients were ambivalent. This might be because the physicians are aware of the infectious nature of COVID-19. Findings from patients also demonstrated that physicians adopting a polite and friendly manner elicited positive responses and emotions whilst they found their physician's body posture reassuring. However, not all patients were impacted in this way; possibly due to the patients' complicated medical condition and negative feedback about the disease the patients got from social media. The findings of the third section echoed a previous descriptive, qualitative study in terms of the importance of an empirically derived model of an 
empathic communication by clinicians with practical implications. ${ }^{34}$

The fourth section of the physicians and the patients' questionnaire was about physicians' skill of using slow and deliberate speech when talking to patients. In Figure 4 and Table 3, (fourth section), the physicians showed a strong positive preference for talking slowly to patients, and not burdening them with details of medical tests and treatment. However, some physicians prefer to explain medical reports and laboratory results comprehensively. This may be because physicians are keen to provide patients with all the details related to their disease to reassure them that the patients are getting the correct information about the condition. Patients indicated that they responded positively to physicians' use of slow and deliberate speech. This finding of the fourth section was in agreement with a previous study of Travaline et al in terms of the importance of that slow down communication provide enough time for patients to absorb new information. ${ }^{21}$

The fifth section of the questionnaire was about the impact of physicians' ability to communicate test results clearly, using ordinary and simple phrases. Figure 5 and Table 3 (fifth section) demonstrate how the physicians were inclined towards simplifying the patients' disease. From the patients' point of view, this approach was helpful to them. This finding of the fifth section was in agreement with previous reports regarding the importance of physicians to avoid long monologues and to keep to short and simple communication statements. ${ }^{21,35}$

The sixth section explored the physician's level of honesty concerning how COVID-19 symptoms develop, and around treatment when talking to patients. In Figure 6 and Table 3 (sixth section), the physicians showed a generally positive trend toward honestly managing the COVID-19 cases. However, some physicians preferred not to be entirely honest with patients with regard to the possible severity of the disease's symptoms, as this could trigger panic in patients about their health conditions. Among patients' however, there was a clear preference indicated for frankness and sympathy from the physician, which substantially impacted patients in the pandemic. This finding of the sixth section was in agreement with previous reports emphasizing the role of verified information in preventing the COVID-19 as a panic disease. ${ }^{21,36}$

The seventh section explored the physicians' skills in giving hope and optimism to patients. The physicians' responses ascribed considerably more importance to providing hope and optimism to COVID-19 patients, than patients' responses did. It is noteworthy that the physicians were neutral with regards to the value of downplaying the disease symptoms when talking to patients. This is possibly because some physicians prefer not to minimize the severity of the symptoms lest the patients show a lack of concern for the seriousness of the disease (Figure 7 and Table 3, seventh section).

Section eight dealt with physicians' positive ability to create optimism with patients through means such as sharing happiness if a patient's condition improves, maintaining eye contact with the patient during the consultation, and respecting social distancing while comforting the patients. The physicians' indicated that they aim to do all of these, while patients' responses expressed appreciation of the physicians' positive efforts in this regard (Figure 8) and (Table 3, eighth section). This finding of the eighth section was in agreement with a previously mentioned report highlighting that an attentive physician will most probably have more satisfied patient. $^{21}$

The ninth section explored the impact of the physicians' negative interactions with patients, which were defined as using firm language with patients who were not seen to be responding to instructions, allowing physicians' work stress to impact communication with patients, and the effect of physicians being distracted by outside influences such as people or the telephone during consultation with patients. The physicians adopted an overall neutral stance towards these behaviours (Figure 9) and (Table 3, ninth section). However, patients reported much stronger negative reactions to such behaviors, with no statistical significance between the two responses.

As COVID-19 is a pandemic disease and different from other conditions, it affects physician-patient communication (PPC). This study examined the psychological effects of Physicians' Communication skills on patients' responses and behavior. Stigmatizing culture might have affected the findings of the study. This study was limited by the fact that there are few respiratory tract specialists in Jordan, which has affected our statistical sample of physicians in this survey. The small population sample of patients in this survey was 248 , which might have influenced this study's statistical power as larger sample represents the whole population statistically better. Furthermore, the surveys in this study were only administered digitally, via google forms; a face-to-face survey is more interactive and may have yielded more accurate data, as some patients in this area (developing countries) may be unfamiliar with digital technology, which might have 
affected their ability to properly fill in the questionnaire. The population of this study was focused geographically on Amman since there is no available demographic database for either patients or physicians in other cities in Jordan. On the other hand, it should be noted that approximately two-thirds of Jordan's total population live in the capital city, Amman. It is recommended that the pandemic medical protocols in Jordan be updated based on this study's findings by building an empirical derived model of physicians' empathic skills of communication with an ability to explore the unexpressed feeling by patients.

\section{Conclusion}

Word selection, range and extent of information provided, language patterns, posture and facial expressions can significantly affect communication quality between physician and patient. To a large extent, this is a conscious choice that a physician makes, to learn and adapt to individual patients in clinical situations. Avoiding communication errors using jargon, not being available to patients, not showing empathy in communication, and being a good listener to patients is highly recommended, and as the results have shown, highly beneficial. Arguably, these skills are not fully developed after completing medical studies or residency. Developing and maintaining a range of communication skills takes time and constant practice. The essential communication elements can help lead to more productive physician-patient meetings and better overall clinical outcomes. This study's findings can be recommended for inclusion by the Health Policy Makers at the Ministry of Health in a Continuous Medical Education (CME) handbook, or guideline of physician-patient communication skills (PPCs). A two-way communication system is also recommended to include both physician to patient, and patient to physician, taking into consideration the psychological effects of both ways. We have to keep in mind that during pandemics, the patients might fear being stigmatized or discriminated against, which could adversely affect the patient-to-physician communication.

\section{Acknowledgments}

The authors would like to acknowledge the support provided by the German Jordanian University, Amman, Jordan. The authors also are grateful to everyone who took the time to complete our questionnaires, both physicians and patients. We would also like to thank the Specialty Hospital for their assistance in distributing the questionnaires and the specialists who reviewed the questionnaires.

\section{Disclosure}

The authors report no financial or other conflicts of interest in this work.

\section{References}

1. WHO. Timeline of WHO's Response to COVID-19; 2020.

2. Bulut JC, Kato Y. Epidemiology of COVID-19. Turkish J Med Sci. 2020;50(SI-1):563-567. doi:10.3906/sag-2004-172

3. Stübinger J, Schneider L. Epidemiology of Coronavirus COVID-19: forecasting the future incidence in different countries. Healthcare. 2020;8:99. doi:10.3390/healthcare8020099

4. Kontoangelos K, Economou M, Papageorgiou C. Mental health effects of COVID-19 pandemia: a review of clinical and psychological traits. Psychiatry Investig. 2020;17:491-505. doi:10.30773/ pi.2020.0161

5. Park SY, Kim B, Jung DS, et al. Psychological distress among infectious disease physicians during the response to the COVID-19 outbreak in the Republic of Korea. BMC Public Health. 2020;20:1811. doi:10.1186/s12889-020-09886-w

6. Kannampallil TG, Goss CW, Evanoff BA, et al. Exposure to COVID-19 patients increases physician trainee stress and burnout. PLoS One. 2020;15(8):e0237301. doi:10.1371/journal.pone.0237301

7. Salari N, Khazaie H, Hosseinian-Far A, et al. The prevalence of sleep disturbances among physicians and nurses facing the COVID-19 patients: a systematic review and meta-analysis. Global Health. 2020;16:92.

8. Chou E, Hsieh YL, Wolfshohl J, Green F, Bhakta T. Onsite telemedicine strategy for coronavirus (COVID-19) screening to limit exposure in ED. Emerg Med J. 2020;37:335-337. doi:10.1136/emermed2020-209645

9. Bains J, Greenwald PW, Mulcare M, et al. Utilizing telemedicine in a novel approach to COVID-19 management and patient experience in the emergency department. Telemed e-Health. 2020. doi:10.1089/ tmj.2020.0162

10. Battineni G, Pallotta G, Nittari G, Amenta F. Telemedicine framework to mitigate the impact of the COVID-19 pandemic. $J$ Taibah Univ Med Sci. 2021. doi:10.1016/j.jtumed.2020.12.010

11. Mittal M, Battineni G, Goyal LM, et al. Cloud-based framework to mitigate the impact of COVID-19 on seafarers' mental health. Int Marit Health. 2020;71:213-214. doi:10.5603/IMH.2020.0038

12. WHO. Coronavirus Disease (COVID-19) Situation Reports. (2021).

13. Patel DS. Body Language: An Effective Communication Tool. 2015.

14. Wong SY, Lee A. Communication skills and doctor patient relationship compliance with medical treatment. Med Bull. 2006;11.

15. Street RL, Gordon H, Haidet P. Physicians' communication and perceptions of patients: is it how they look, how they talk, or is it just the doctor? Soc Sci Med. 2007;65:586-598. doi:10.1016/j. socscimed.2007.03.036

16. Reddy B, Gupta A. Importance of effective communication during COVID-19 infodemic. J Fam Med Prim Care. 2020;9:3793.

17. Bardosono S, Pansawira P, Ratih MP. Effective communication skill: doctor - patient consultation. World Nutr J. 2018;2:2580-7013. doi:10.25220/WNJ.V02.i1.0007

18. Biglu M, Nateqv F, Ghojazadeh M, Asgharzadeh A. Communication skills of physicians and patients' satisfaction. Mater Socio Medica. 2017;29:192.

19. Kee JWY, Khoo HS, Lim I, Koh MYH. Communication skills in patient-doctor interactions: learning from patient complaints. Heal Prof Educ. 2018;4:97-106. 
20. Ha JF, Longnecker N. Doctor-patient communication: a review. Ochsner J. 2010;10:38-43.

21. Trayaline JM, Ruchinskas R, D’Alonzo GE. Patient-physician communication: why and how. J Am Osteopathic Assoc. 2005;105:13-18.

22. Ghosh A, Sharma K, Choudhury S. COVID-19 and physician-patient relationship: potential effects of 'masking', 'distancing' and 'others'. Fam Pract. 2020. doi:10.1093/fampra/cmaa092

23. Back A, Tulsky JA, Arnold RM. Communication skills in the age of COVID-19. Ann Intern Med. 2020;172:759-760. doi:10.7326/M201376

24. Finset A, Bosworth H, Butow P, et al. Effective health communication - a key factor in fighting the COVID-19 pandemic. Patient Educ Couns. 2020;103:873-876. doi:10.1016/j.pec.2020.03.027

25. Rubinelli S, Myers K, Rosenbaum M, Davis D. Implications of the current COVID-19 pandemic for communication in healthcare. Patient Educ Couns. 2020;103:1067-1069. doi:10.1016/j.pec.2020. 04.021

26. Constand MK, MacDermid JC, Dal Bello-Haas V, Law M. Scoping review of patient-centered care approaches in healthcare. BMC Health Serv Res. 2014;14:271. doi:10.1186/1472-6963-14-271

27. Zill JM, Christalle E, Müller E, et al. Measurement of physician-patient communication-a systematic review. PLoS One. 2014;9:12. doi:10.1371/journal.pone.0112637

28. ACOG. Effective Patient-Physician Communication. Available from: https://www.acog.org/clinical/clinical-guidance/committee-opinion /articles/2014/02/effective-patient-physician-communication.

Accessed March 29, 2021.
29. Sun C, Zou J, Zhao L, et al. New doctor-patient communication learning software to help interns succeed in communication skills. BMC Med. Educ. 2020;20:8. doi:10.1186/s12909-019-1917-z

30. Marschollek P, Bąkowska K, Bąkowski W, Marschollek K, Tarkowski R. Oncologists and breaking bad news-from the informed patients' point of view. The evaluation of the SPIKES protocol implementation. J Cancer Educ. 2019;34:375-380. doi:10. 1007/s13187-017-1315-3

31. Milton AC, Mullan B. Views and experience of communication when receiving a serious mental health diagnosis: satisfaction levels, communication preferences, and acceptability of the SPIKES protocol. $J$ Ment Heal. 2017;26:395-404. doi:10.1080/09638237.2016.120 7225

32. World Medical Association. World Medical Association Declaration of Helsinki. JAMA. 2013;310:2191.

33. WMA The World Medical Association. Declaration of Helsinki 1989. Available from: https://www.wma.net/what-we-do/medical-ethics /declaration-of-helsinki/doh-sept1989/. Accessed January 23, 2021.

34. Suchman ALA. Model of empathic communication in the medical interview. JAMA. 1997;277:678. doi:10.1001/jama.1997.035403200 82047

35. Mostofsky E, Dunn JA, Hernández-Díaz S, Mittleman MA. Patient and physician preferences for reporting research findings. Fam Med. 2019;51:502-508. doi:10.22454/FamMed.2019.400835

36. The Lancet. COVID-19: fighting panic with information. The Lancet. 2020;395:537.
Patient Preference and Adherence

\section{Publish your work in this journal}

Patient Preference and Adherence is an international, peer-reviewed, open access journal that focusing on the growing importance of patient preference and adherence throughout the therapeutic continuum. Patient satisfaction, acceptability, quality of life, compliance, persistence and their role in developing new therapeutic modalities and compounds to optimize clinical outcomes for existing disease

\section{Dovepress}

states are major areas of interest for the journal. This journal has been accepted for indexing on PubMed Central. The manuscript management system is completely online and includes a very quick and fair peer-review system, which is all easy to use. Visit http:// www.dovepress.com/testimonials.php to read real quotes from published authors. 